\title{
Strongyloides stercoralis infection in former Far East prisoners of war
}

\author{
GEOFFREY V GILL, DION R BELL
}

\section{Summary and conclusions}

Out of 602 consecutive people who had been prisoners of war in the Far East and were screened for tropical diseases, $88(15 \%)$ were found to have Strongyloides stercoralis infection a mean period of 30 years after their return from the tropics. The classical strongyloid creeping eruption was the most common symptom $(84 \%)$, while gastrointestinal disturbances were rare $(5 \%)$. Thiabendazole was highly effective in eradicating the infection.

Strongyloidiasis is an important condition, as when the host is immunosuppressed fatal hyperinfection may occur. Many undiagnosed cases of strongyloidiasis must exist among former prisoners of war, and it is thus important to identify and treat these patients.

\section{Introduction}

Nematode worms of the species Strongyloides are widely distributed geographically, but most human infections are due to $S$ stercoralis, which is confined to the tropics. All cases occurring in Britain are imported. The parasite has a complex dual life cycle that includes parasitic and free-living cycles. ${ }^{1}$ Infections in man arise when soil larvae penetrate the skin, pass in the blood to the lungs, and then ascend the tracheobronchial tree to be swallowed. In the duodenum and proximal jejunum female worms lay eggs that immediately liberate rhabditiform larvae. These larvae either pass out in the stool or develop sufficiently to cause autoinfection by penetrating the bowel mucosa or perianal skin, migrating to the lungs, and eventually developing into adult worms in the gut. Figure 1 shows a rhabditiform larva of $S$ stercoralis as seen on microscopy of a stool specimen.

Strongyloidiasis may be asymptomatic or cause abdominal pain and diarrhoea ${ }^{2}$ or even malabsorption. ${ }^{34}$ In patients immunosuppressed by drugs or disease a severe "hyperinfective" form of the condition may result, in which massive larval tissue invasion causes an often fatal syndrome of diarrhoea, malabsorption, septicaemia, and encephalopathy. ${ }^{5-7}$

$S$ stercoralis infection was first reported in Britain in 1949, when the disease was discovered in prisoners of war (POWs) of the Japanese repatriated from the Far East. ${ }^{8}{ }^{9}$ The infection was associated often with a linear urticarial rash resembling cutaneous larva migrans, but because of its faster movement it became known as "larva currens" (see fig 2). Over 30 years after their return from the tropics these former Far East POWs (ex-POWs) may still suffer from strongyloidiasis with its

\footnotetext{
Department of Tropical Medicine, Liverpool School of Tropical Medicine, Liverpool L3 5QA

GEOFFREY V GILL, MRCP, DTM\&H, senior registrar (present address: Department of Clinical Biochemistry, Royal Victoria Infirmary; Newcastle upon Tyne NE1 4LP)

DION R BELL, FRCP, DTM\&H, senior lecturer
}

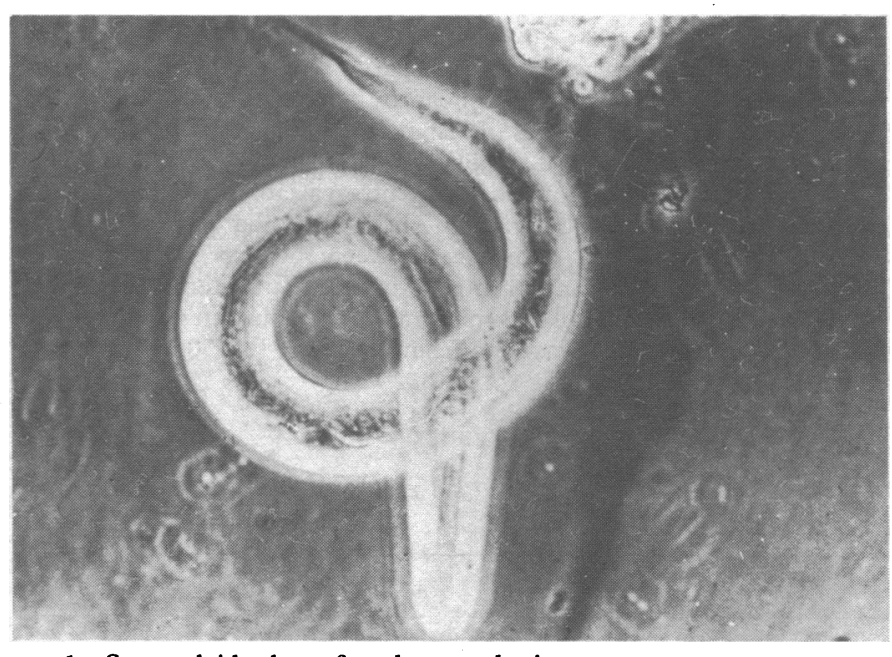

FIG 1-Strongyloides larva found on stool microscopy.

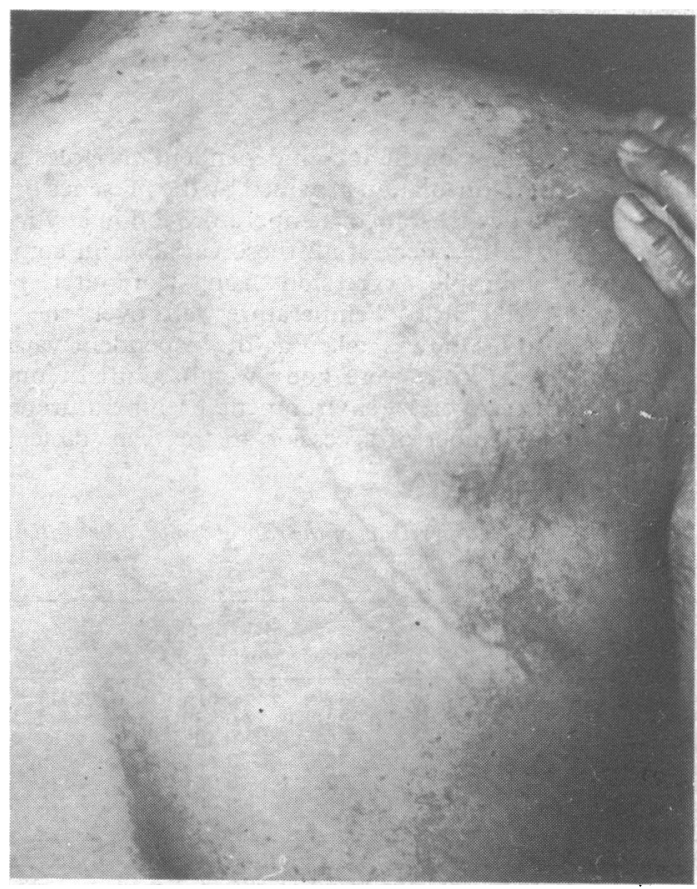

FIG 2-Typical rash produced by migrating strongyloides larvae.

characteristic rash. ${ }^{10}$ This troublesome and potentially dangerous $\stackrel{\frac{\Omega}{\mathbb{D}}}{\stackrel{\circ}{\circ}}$ infection can now, however, be treated relatively easily. In this paper, therefore, we draw attention to the continuing problem 0 of strongyloidiasis in Britain by reporting our findings in $88 \frac{0}{0}$ cases seen during the past 11 years.

\section{Patients and methods}

A total of 602 ex-POWs attended for tropical-disease health checks at the Liverpool School of Tropical Medicine during the 11 years 
January 1968 to December 1978. The patients came from various parts of the north of England and north Wales and were each admitted for about one week for intensive investigations. Their mean age was 58 years (range 46-69) at the time of presentation. All had been in good health before the second world war, and none had been back to the tropics since repatriation in 1945. The mean time since tropical exposure was 30 years (range 23-33). Important parasitological investigations undertaken were microscopy and culture of three separate stool specimens, blood eosinophil count, and a serum complement fixation test (CFT) against an Ascaris lumbricoides antigen.

\section{Results}

\section{INFECTION RATE}

Calculation of the infection rate was complicated by the fact that in February 1977, at our suggestion, the welfare organisations for ex-POWs circulated their membership with descriptions of the strongyloid rash and urged possible sufferers to seek referral to a tropical-disease unit. This resulted in an increased number of cases in late 1977 and early 1978 , and altogether we saw 88 cases during the 11-year study period. Before February 1977, however, none of the patients had any idea that they still harboured parasitic worms, and the infection rate up to this time was 53 out of $443(12 \%)$. This may be regarded as representing the true prevalence. Such figures, however, probably underestimate the problem to some extent, as negative investigations at any time do not necessarily exclude the diagnosis, as shown by the following case.

Case 1-An ex-POW had been assessed for tropical diseases in 1972, when all parasitological investigations (including three stool examinations, blood eosinophil count, and CFT) were negative. In 1977 he received a circular from his Far East Club about strongyloidiasis and realised that he had suffered from this since being in the Far East. He requested a further tropical-disease check, and when he was seen in 1978 the rash he described was quite typical, though it was not witnessed. Investigations disclosed a negative CFT and no blood eosinophilia, but two out of three stool specimens contained larvae of $S$ stercoralis. A course of thiabendazole cured his rash, from which he had suffered for over 33 years.

In addition to those subjects found to have active strongyloidiasis, a further 16 had histories of the infection diagnosed at other centres (often soon after repatriation). These infections had either resolved spontaneously or been eventually treated. Again taking figures up to February 1977 to avoid selective bias, this gives a figure of 69 out of 443 , or $16 \%$, as the total infection rate with $S$ stercoralis among ex-POWs since repatriation.

\section{PRESENTATION}

The presenting feature in 74 of the 88 patients $(84 \%)$ was a history of the typical creeping eruption; in 24 of these patients $(32 \%$ of those with rash) the eruption was witnessed in hospital. In 14 patients $(16 \%)$ the infection was asymptomatic and diagnosed only when larvae were found in the stool.

The strongyloid rash (fig 2) takes the form of a raised, serpiginous urticarial wheal surrounded by a flare. The track is intensely itchy and represents the migratory pathway of a larva. It moves at a rate of about $5-10 \mathrm{~cm}$ per hour, which is many times faster than the similar cutaneous larva migrans caused by non-human hookworms. The lesions are also more transient, often disappearing after a few hours. The eruption tends to affect the buttocks, groin, and trunk and occasionally the neck and thighs; the arms, legs, and face are rarely affected. Lesions tend to occur in crops over a few days, with often weeks or months of freedom between. In all our cases the rashes began while the patients were in the Far East or immediately on their return to Britain. Many ex-POWs did not volunteer complaints of their rash until asked direct, as they had "got used to them," or been told that they had other conditions, or that it "was their nerves."

Case 2-A 57-year-old ex-POW said during interview that he was under treatment from his doctor for urticaria. On close questioning we found that the rash had begun while he was in the Far East and consisted of "red blotches and wriggly lines" that moved over his trunk and buttocks, were intensely itchy, and lasted for between one hour and one day. He thought the eruption was brought on by hot weather and exertion. While he was in hospital a classical strongyloid eruption was witnessed over the right side of his trunk, disappearing the same day. Larvae of $S$ stercoralis were found in his stool, he had a blood eosinophilia of $17 \%$, and a CFT was negative. He was given a course of thiabendazole while in hospital, and six months later reported that the rash had disappeared and he felt a general improvement in health.

Case 3-On interview a 52-year-old ex-POW had no particular complaints. When examined, however, a classical larva currens eruption was seen tracking over the lower right side of his abdomen. When questioned on this he said that he had "had it on and off since the war, but didn't think it was important." During his subsequent admission $S$ stercoralis larvae were found in his stool and he was given a course of thiabendazole, after which the rash disappeared.

Abdominal symptoms were rare, only four patients (5\%) having such complaints. The symptoms were intermittent diarrhoea and abdominal pain, and in one case possible malabsorption.

Case 4-A 60-year-old ex-POW had suffered from a typical strongyloid rash since the war, which often interfered with his sleep. He also had persistent diarrhoea and had lost weight (his enlistment weight was recorded as $71 \mathrm{~kg}$ and his present weight $55 \mathrm{~kg}$ ). He had $26 \%$ blood eosinophilia, a positive helminth CFT, and impaired xylose absorption. One year after treatment with thiabendazole he was much improved with no further diarrhoea or rash, and his weight had increased.

\section{STOOL EXAMINATION}

Results of stool examination (microscopy and culture of three specimens for each ex-POW) were available for 87 patients, and larvae were found in $37(43 \%)$. In 14 of these cases larvae were isolated only after culture and were not seen on direct microscopy. Stools were negative in the remaining 50 patients $(57 \%)$, though in seven cases culture was not done. Other workers have had difficulty in finding larvae in the stools of patients with strongyloidiasis, ${ }^{11}{ }^{12}$ and Napier mentions an ex-POW in whom the diagnosis was made only when the twelfth stool had been examined microscopically. ${ }^{9}$ We had a similar experience.

Case 5-A 53-year-old ex-POW gave a history of strongyloidiasis that had been successfully treated. His records showed that he had first presented in 1955 with a typical strongyloid rash dating back to the war. At that time he had $14 \%$ eosinophilia in his blood and stools were positive for $S$ stercoralis larvae, but no treatment was then available. He was again admitted in 1963, still suffering from the same rash. He now had $22 \%$ eosinophilia, but 15 separate stool specimens were negative for larvae. He was eventually given a course of dithiazanine, after which his rash disappeared and his eosinophils returned to normal.

\section{EOSINOPHILIA}

Blood eosinophil counts were obtained in 86 patients and were raised ( $5 \%$ or more of the total white cell count) in $64(74 \%)$. In those with eosinophilia the mean value was $13 \%$ (range $5-31 \%$ ), and in the whole group the mean was $10 \%$ (range $0-31 \%$ ). Interestingly, higher eosinophil counts tended to occur in those who had negative stools. Thus eosinophilia occurred in $53 \%$ of those with positive stools but in $88 \%$ of those in whom the stool was negative $\left(\chi^{2}=12.864\right.$, $\mathrm{P}<0.0005)$. All other clinical and investigative features showed no significant correlations.

\section{COMPLEMENT FIXATION TEST}

The helminth CFT was done in 60 cases and was positive in 27 $(45 \%)$.

\section{RESPONSE TO TREATMENT}

Eighty-three patients received hospital treatment, and in all cases thiabendazole was used at a dose of $25 \mathrm{mg} / \mathrm{kg}$ twice daily for three days. Four early patients had been initially treated with levamisole, but this failed and they were retreated with thiabendazole. Of the 74 symptomatic patients, 14 were lost to follow-up; the remaining 60 were followed up by outpatient visit, readmission, or postal questionnaire. The mean time of reassessment after treatment was 29 months (range 5-121). The results of follow-up were that 51 patients were cured $(85 \%)$, seven were improved $(12 \%)$, and two 
were unchanged $\left(3^{\prime \prime}{ }_{0}\right)$. Those with bowel symptoms responded similarly to those with rash. This favourable response rate with thiabendazole is similar to that found by Bezjak ${ }^{13}$ and, we think, confirms this drug as the treatment of choice in human strongyloidiasis. Side effects are quite common and may be troublesome but rarely necessitate stopping the treatment.

Case 6-Ten months after successful treatment for strongyloidiasis with thiabendazole an ex-POW wrote and described his experiences: "the tablets made me feel sick and a little dizzy, like I was drunk all the time. At night I had vivid dreams, and all the time my body and urine smelled very strange. I remember finding the treatment unpleasant, but it is a small price to pay. It's marvellous to think that after all these years the skin irritation is gone."

\section{Discussion}

The most striking features of this series are the frequency with which the strongyloid creeping eruption was the presenting feature $\left(84^{\circ}{ }_{0}\right)$ and the low incidence of bowel symptoms $\left(5^{\circ}{ }_{0}\right)$. This contrasts sharply with other series, where gastrointestinal disturbance has been the major presenting symptom. ${ }^{214}$ The reason for this discrepancy probably lies in the somewhat abnormal natural history of the infection in our patients. Previous reports have concerned patients with relatively acute infections in endemic areas, whereas our ex-POWs had been infected for prolonged periods and the parasite depended on autoinfection rather than a soil reservoir for its persistence. This selection of the autoinfective parasitic cycle will cause a relative increase in migratory tissue larvae and a decrease in larvae passing down the bowel. This redistribution of larvae could explain the frequent presentation with rash and low incidence of bowel disorders; and also why those whose stools were negative for larvae had significantly higher eosinophil counts (negative stools implying large numbers of tissue larvae, which presumably evoke a greater eosinophil response). It does not, however, explain why our patients had generally normal serum IgE concentrations, ${ }^{15}$ since others have found extremely high concentrations in more acute cases. ${ }^{16}$

Our experience suggests that the strongyloid rash, especially if witnessed, is pathognomonic. When the diagnosis is suspected but stools are negative then appreciable blood eosinophilia is sufficient to indicate a trial of thiabendazole, after which disappearance of both rash and eosinophilia will generally provide the final confirmation. In cases that are particularly difficult to diagnose an alternative to multiple stool testing is the "duodenal thread" technique, which has proved so useful in diagnosing giardiasis. This method is superior to both stool microscopy and duodenal intubation in $S$ stercoralis infection. ${ }^{11}{ }^{12}$ The CFT may occasionally be useful in providing additional supportive evidence of infection, but it gives too many falsenegative results to be reliable. The results are no better when $S$ fulleborni antigen is used instead of $A$ lumbricoides. ${ }^{17}$

Diagnostic difficulties such as those encountered in case 1 mean that our assessment of the infection rate as being $12^{\circ}$ o of all those who were POWs in the Far East is probably too low. Additionally, 28 of our 602 subjects $\left(5^{\circ}{ }_{0}\right)$ had appreciable blood eosinophilia (mean $10^{\circ}{ }_{0}$, range $5-25^{\circ}{ }_{0}$ ) with no other clinical or investigative features of parasitic infection. Some of this group may well have had asymptomatic strongyloidiasis (particularly as our results show that negative stools are significantly associated with eosinophilia). Overall, we think that at least $15-20^{\circ}{ }_{0}$ of all former Far East POWs in Britain probably have $S$ stercoralis infection.

About 38000 POWs survived their captivity in the Far East to be repatriated to Britain in 1945. How many are still alive today is not known, but even given that under half have survived and that the strongyloidiasis infection rate among them is $12^{\circ}{ }_{0}$, then this gives, at a very conservative estimate, between one and two thousand cases in Britain, nearly all as yet undiagnosed. A course of thiabendazole could end years of troublesome skin irritation for these men and also eradicate this most unsafe infection. The danger of hyperinfection is very real, especially with increasing use of corticosteroids, which are potent precipitants of this serious syndrome. ${ }^{18-20}$ Deaths from hyperinfection may well have occurred in the past without being diagnosed when steroids have been given to ex-POWs with undiagnosed strongyloidiasis. For the present, it is important to encourage all people who were POWs in the Far East to attend a school of tropical medicine for investigation, and to avoid treating them with steroids until they are known to be free of the tenacious and ubiquitous parasite.

We are grateful to the other physicians of the Liverpool School of Tropical Medicine, past and present, for allowing us to study their patients.

Requests for reprints should be addressed to DRB.

\section{References}

${ }^{1}$ Fulleborn, F, Archiv für Schiffs- und Tropenhygiene, 1914, 18, 26.

2 Hinman, E H, Transactions of the Royal Society of Tropical Medicine and Hygiene, 1937, 30, 531.

${ }^{3}$ Milner, P F, et al, Gut, 1965, 6, 574.

O'Brien, W, Transactions of the Royal Society of Tropical Medicine and Hygiene, 1975, 69, 69.

${ }^{5}$ Rivera, E, et al, Annals of Internal Medicine, 1970, 72, 199.

${ }^{6}$ Adam, M, et al, British Medical fournal, 1973, 1, 264.

7 Purtilo, D . T, Meyers, W M, and Connor, D H, American fournal of Medicine, 1974, 56, 488

${ }^{8}$ Caplan, J P, British Medical fournal, 1949, 1, 396.

${ }^{9}$ Napier, L E, Fournal of Tropical Medicine and Hygiene, 1949, 52, 46.

10 Gill, G V, Bell, D R, and Reid, H A, British Medical fournal, 1977, 1, 1007.

${ }^{11}$ Beal, C B, et al, American fournal of Tropical Medicine and Hygiene, 1970, 19, 349.

12 Bezjak, B, American fournal of Digestive Diseases, 1972, 17, 848.

${ }_{13}$ Bezjak, B, American fournal of Tropical Medicine and Hygiene, 1968, 17, 733.

14 Yoeli, M, et al, Transactions of the Royal Society of Tropical Medicine and Hygiene, 1963, 57, 336.

${ }^{15}$ Gill, G V, Bell, D R, and Fifield, R, Clinical and Experimental Immunology. In press.

${ }^{16}$ Bezjak, B, American fournal of Tropical Medicine and Hygiene, 1975, 24, 945.

1 Kurniawan, L, MSc dissertation. Liverpool University, 1977.

18 Cruz, T, Reboucas, G, and Rocha, H, New England fournal of Medicine, 1966, 275, 1093.

19 Willis, A J P, and Nwokolo, C, Lancet, 1966, 1, 1396.

${ }^{20}$ Neefe, L I, et al, American fournal of Medicine, 1973, 55, 832.

(Accepted 20 fuly 1979)

ONE HUNDRED YEARS AGO With characteristic regard for the welfare of public and beneficent institutions for British subjects, their Royal Highnesses the Prince and Princess of Wales took the opportunity of their recent visit to Paris to pay a detailed and prolonged ON visit to the New Hertford British Hospital in that city. The visit was no mere visit of ceremony, but occupied upwards of an hour and three-quarters; and the senior physician, Sir John Rose Cormack, N writes to us: "The visit of their Royal Highnesses was most pleasant $\mathrm{N}$ to all of us; and their minute exploration of all the hospital arrangements, and of ali that was to be inspected, was extraordinary." From another source, we learn that the Prince and Princess expressed their great admiration of the architectural beauty of the building, which was designed by $M$ Sanson from the inspiration of the thirteenth century ecclesiastical "Hotels de Dieu," usually situate at the gates of the towns; and also their appreciation of the excellent arrangements for providing abundance of air and light, and the sound arrangements for the comfort and well-being of the patients. A convalescent standing at his bedside attracted the Prince's notice by his military bearing. "You have been a soldier," said the Prince. "Yes, sir," replied the patient, "and I was one of your Royal Highness's escort at Delhi." Their Royal Highnesses were received by the British Ambassador, Lord Lyons, and the two physicians of the hospital, Sir John Rose Cormack and the Honourable Alan Herbert, MD, and the principal officers of the hospital were presented. In accordance with the request of Sir Richard Wallace, the munificent founder of the hospital (who was detained in England by the state of his health), His Royal Highness named the principal ward "Albert Edward," and the principal female ward, "Alexandra." (British Medical fournal, 1879.) 